\title{
Correction to: Magnetic Properties of Electroformed Ni and Ni-Fe for Micromagnetic MEMS Applications
}

\author{
S. K. Bagaria ${ }^{1}$. C. Periasamy ${ }^{1}$
}

Published online: 22 November 2017

(C) Springer Science+Business Media, LLC, part of Springer Nature 2017

Correction to: J Supercond Nov Magn (2015) 28:3357-3363

https://dx.doi.org/10.1007/s10948-015-3168-5

The experimental work, particularly the SEM study, presented in "Magnetic properties of electroformed $\mathrm{Ni}$ and $\mathrm{Ni}-\mathrm{Fe}$ for Micromagnetic MEMS Applications" published in the Journal of Superconductivity and Novel Magnetism, 28:3357-3363 (2015) was performed at the CSIRCEERI Laboratory, Pilani, India. The authors would like to acknowledge MEMS and Microsensors Group, CSIRCEERI, Pilani, India, for providing SEM facility.

The online version of the original article can be found at https://dx.doi.org/10.1007/s10948-015-3168-5.

S. K. Bagaria

sanjaybagaria.ece@mnit.ac.in

1 Department of Electronics and Communication

Engineering, Malaviya National Institute of Technology,

J.L.N. Marg, Jaipur 302017, India 